\title{
Pre-EUCREX Intercomparison of Airborne Humidity Measuring Instruments
}

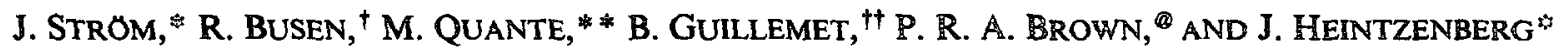 \\ * Department of Meteorology, Stockholm University. Stockholm, Sweden \\ ${ }^{\dagger}$ DLR Oberpfaffenhofen, Institute of Atmospheric Physics, Wessling, Germany \\ * *GKSS Forschungszentrum, Institut für Physik, Geesthacht, Germany \\ ${ }^{{ }^{\dagger}}$ Laboratoire de Météorologie Physique, Université Blaise-Pascal, Clermont-Ferrand, France \\ -U.K. Meteorological Office, Meteorological Research Flight, DRA-Famborough, Hampshire, England
}

7 September 1993 and 11 February 1994

\begin{abstract}
During the pre-EUCREX (European Cloud and Radiation Experiment) intercomparison of airborne instrumentation in January 1992, nine hygrometers mounted on three different aircraft were compared. Although the different instruments are based on completely different principles and the three aircraft have very different flying characteristics, humidity data from both vertical profiles as well as horizontal flight legs showed good agreement. Despite the different aircraft limitations the intercomparison was done with the aircraft in close formation. In terms of relative differences in mixing ratio, most instruments agreed to within $\pm 5 \%$ for values down to about $0.1 \mathrm{~g} \mathrm{~kg}^{-1}$. For mixing ratios between 0.03 and $0.1 \mathrm{~g} \mathrm{~kg}^{-1}$ most instruments agreed to within $\pm 15 \%$. Systematic differences between the instruments suggest that in joint experiments where data will be shared, the same algorithms for evaluating and converting humidity parameters should be used whenever possible.
\end{abstract}

\section{Introduction}

The demands on hygrometers may be very different, depending on the atmospheric process one wishes to study. The performance of any such instrument can be characterized by its accuracy, precision, response time, lag time, and measuring range. The platform used (ground based, aircraft, rocket, or balloon) for the hygrometer may also impose constraints on the instrument, such as that it be small and inexpensive. For the European Cloud and Radiation Experiment (EUCREX), several aircraft and instruments are operated by research groups from different countries (Raschke 1988; Raschke et al. 1991). For the validation and interpretation of airborne measurements, intercomparisons of instruments are conducted during and between measuring campaigns.

For these reasons, three aircraft met in January 1992 at Farnborough airfield, United Kingdom, to intercompare primarily humidity instruments but also sensors measuring wind, position, radiance, and microphysical cloud properties. The sensors were operated from about $150 \mathrm{~m}$ above the sea surface up to $9000 \mathrm{~m}$ over the Celtic Sea and Cornwall peninsula, United Kingdom. During the intercomparison, the three aircraft were mostly in close formation with about $10 \mathrm{~m}$ between wingtips. However, during low-level flights in

Corresponding author address: Dr. Johan Ström, Department of Meteorology, Stockholm University, Arrhenius Laboratory, S-106 91 Stockholm, Sweden. the cloudy boundary layer, a greater distance ( several hundred meters) had to be used for safety reasons. The synoptic weather situation during the campaign was characterized by anticyclonic flow and low wind speeds extending throughour the troposphere over a large part of Europe. In the sampling area, the only cloud present during the intercomparison was broken stratocumulus over the sea, trapped by the subsidence inversion. However, only out-of-cloud segments were used in the intercomparison of the hygrometers.

The three aircraft used as platforms for the hy. grometers were the French twin-engine turboprop Merlin operated by the Meteorological Aviation Center, Bretigny, France, the German twin-engine jet Falcon operated by the German Aerospace Research Establishment (DLR), and the British fourengine C-130 Hercules operated by the U.K. Meteorological Office, Meteorological Research Flight. The different aircraft and the location of the sensors are presented in Fig. 1. In this paper we present an intercomparison of airborne hygrometers for use in the free troposphere, where we expect temperature and humidity to be low. The principles used by the different instruments can be divided into optical (absorption, emission), thermal (temperature control) dewpoint temperature, and electrical (capacitance, resistance), where the optical principle may be regarded as a direct measurement of the water vapor content in the air. Section 2 provides a brief description of each instrument used in the intercomparison and selected results of their intercomparison. 

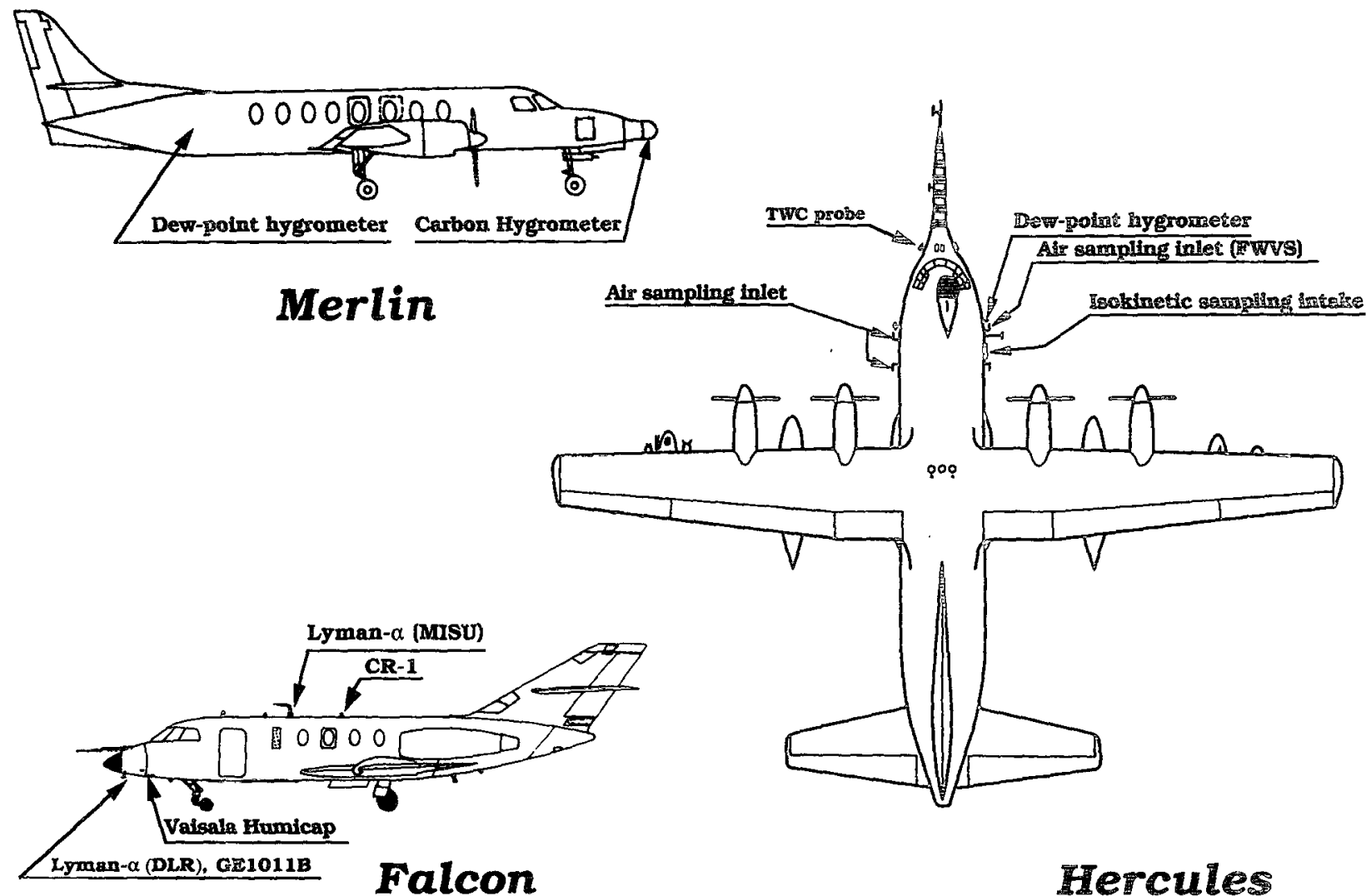

FIG. 1. The position of the sampling inlets for the hygrometers on the different aircraft.

\section{Hygrometers}

a. General Eastern (GE) $1011 \mathrm{~B}$

This instrument is used by many groups and was installed on all three aircraft. The GE1011B (General Eastern Instruments, Watertown, Massachusetts ) is an automatic cooled-mirror dew- / frost-point sensor. The mirror surface is cooled by a thermoelectric cooler, which is servo controlled to maintain a dew deposit on the mirror. This deposit is then detected by an optical device. Because of the ambiguous temperature response when the condensate changes phase from liquid too solid and vice versa, the instrument cannot differentiate between dew- and frost point during the phase change. The instrument has a quoted accuracy of $\pm 0.3^{\circ} \mathrm{C}$ at a temperature of $0^{\circ} \mathrm{C}$, with a resolution of $0.1^{\circ} \mathrm{C}$. Its time constant varies from about 1 to $2 \mathrm{~s}$ at high absolute humidities to several minutes at temperatures close to its lower limit of around $-60^{\circ} \mathrm{C}$. One of the two GE1011B's mounted on the Merlin and the GE1011B mounted on the Falcon malfunctioned and were not used in the intercomparison.

\section{b. The cryogenically cooled-mirror hygrometer (CR-1)}

The CR-1 hygrometer is built by Buck Research (Buck and Clark 1991) and was developed in coop- eration with the German Aerospace Research Establishment (DLR). It is based on the same principle as the GE1011B hygrometer, but uses liquid nitrogen to cool the mirror instead of a thermoelectric element. This results in a short response time from a fraction of a second to several seconds at low frost points. The operating frost-/dewpoint range is between $-90^{\circ}$ and $30^{\circ} \mathrm{C}$ and the readout accuracy is $0.2^{\circ} \mathrm{C}$.

\section{c. Lyman- $\alpha$ hygrometer}

The Lyman- $\alpha$ hygrometer measures the absorbed UV radiation by water vapor and thus gives a direct measurement of the concentration of water vapor in the sample cell. Two different Lyman- $\alpha$ hygrometers were used during this intercomparison.

The hygrometer operated by the Department of Meteorology Stockholm University (MISU) is an integral part of the counterflow virtual impactor (CVI) payload described by Noone et al. (1988). The Lyman- $\alpha$ (MISU) is a custom-built dual-beam instrument that uses a single light source for both a sample and a reference chamber (Zuber and Witt 1987). The ratio of the transmitted intensities ( $I_{\text {samp }}$ over $I_{\text {ref }}$ ) is used to calculate the water vapor content in the sample cell. This arrangement compensates for any drift or variation in lamp intensity. At ground level the dry reference 
air for this instrument was measured to correspond to a frost point of $-80^{\circ} \mathrm{C}$ as determined by the cryogenically cooled-mirror hygrometer (CR-1).

The instrument operated by DLR is a single chamber Lyman- $\alpha$ hygrometer L-5, manufactured by Buck Research (Buck 1985; Busen et al. 1991). To compensate for drift in the light source, the Lyman- $\alpha$ (DLR) is software adjusted in real time against the CR-1. Thus, the instrument does not yield a completely independent measurement.

\section{d. The fluorescence water vapor sensor (FWVS)}

This instrument was designed by the Atmospheric Chemistry group of the U.K. Meteorological Office. It employs the principle described by Kley and Stone (1978). The instrument records the ratio between the fluorescence emission from excited $\mathrm{OH}$ radicals produced by the photodissociation of water molecules by a Lyman- $\alpha$ source and the signal from a long pathlength Lyman- $\alpha$ absorption cell. Provided that the absorption coefficient for water vapor at the Lyman- $\alpha$ wavelength is known, the introduction of small but otherwise unknown quantities of water vapor into the sample volume produces a change in signal that can be used to derive an absolute calibration. This is independent of any changes in the lamp intensity and any secondary water vapor standards. The device is controlled by a microprocessor and a short-path $\mathrm{Ly}$ man $\alpha$ absorption cell that is used to provide data at higher humidities. It has an operational dewpoint range from about $-80^{\circ}$ to $+30^{\circ} \mathrm{C}$.

\section{e. The total water content hygrometer (TWC)}

The total water hygrometer is fully described by Nicholls et al. (1989). It employs a ceramic matrix heater element to evaporate any condensed water. The humidity of the resulting warm, moist air is then measured by a Lyman- $\alpha$ absorption hygrometer of the type described by Buck (1985). Because of the inherent drift associated with this type of hygrometer, it is adjusted against the GE1011B hygrometer during cloud-free segments. The absolute accuracy of the instrument is therefore restricted to that of the GE1011B. The time response is on the order of milliseconds in clear air. In this study the TWC hygrometer operates in an identical fashion to other Lyman- $\alpha$ hygrometers, since the humidity intercomparison was done for cloud-free segments only.

\section{f. The Vaisala Humicap instrument}

The Humicap HMP11 (Vaisala, Helsinki, Finland) is a thin-film capacitor, where the conductivity of the dielectric medium is changed by the presence of water molecules. This instrument is known to have long time constants at high relative humidities, and even more so at low temperatures.

\section{g. The carbon plate hygrometer}

Similar to the Humicap, the carbon plate hygrometer (Méteo-France) uses the variation in the resistance due to the absorption of water molecules by a film of carbon (e.g., Semiond 1977). The carbon instrument is similar to that described by Morrissey and Brousaides (19\%0). The instrument is known to be sensitive to changes in temperature and the output signal suffers from hysteresis.

\section{Comparison flights}

Three flights were conducted on 21, 22, and 23 January 1992. On 22 January, during the performance of a box pattern at $6000 \mathrm{~m}$, an interesting near-step change in the humidity was observed. The change in amtient mixing ratio between 0.05 and $0.2 \mathrm{~g} \mathrm{~kg}^{-1}$ took place over a distance of about $20-30 \mathrm{~km}$. It is interesting to note that a corresponding change in the signal was observed by the infrared radiometers facing upward on the Falcon and the Hercules. The temperature at flight level was $-23^{\circ} \mathrm{C}$. For intercomparison purposes, all data were converted from their original units to mixing ratios. Time series of water vapor mixing ratios observed by the different hygrometers between 1320 and 1345 UTC are plotted in Figs. 2a-h.

An inspection of these time series alone yields valuable information about the performance of the instruments. With the exception of the carbon plate hygrometer, we see the same general variation of the humidity in all instruments. The humid region was even resolved by the Humicap instrument but seriously overestimated by about $0.25 \mathrm{~g} \mathrm{~kg}^{-1}$. Small-scale features, like the hump during the first $150 \mathrm{~s}$ and the structures at 380 and $460 \mathrm{~s}$ after the start of the time series, are also distinguishable in most instruments. By comparing the different time series in Figs. $2 a-h$ in terms of humidity fluctuations, the Lyman- $\alpha$ (DLR) measures what appear to the most authentic time series without noise or damped signal. However, the average values are biased toward those measured by the CR-1 due to the in-flight calibration of the Lyman- $\alpha$ (DLR). The signal from the TWC probe and especially the signal from the FWVS appear to be noisy. No explanation for this noise problem of the FWVS exists. The limitation in bit resolution seems to be the most serious problem for the TWC probe. This resolution problem is most evident during the first $600 \mathrm{~s}$ of the TWC-probe time series, when the signal jumps in discrete steps. The performance of the TWC probe can easily be improved by using a 16-instead of 12-bit digitization and/or decreasing the dynamic range of the instrument. The signals from the two GE1011B instruments are much smoother. This damped signal is a result of the time constant in the dewpoint instruments that filter out small-scale variations. It is clear that the CR-1 hygrometer, which uses the same principle as the GE1011B but is cryogenically cooled, has a much 

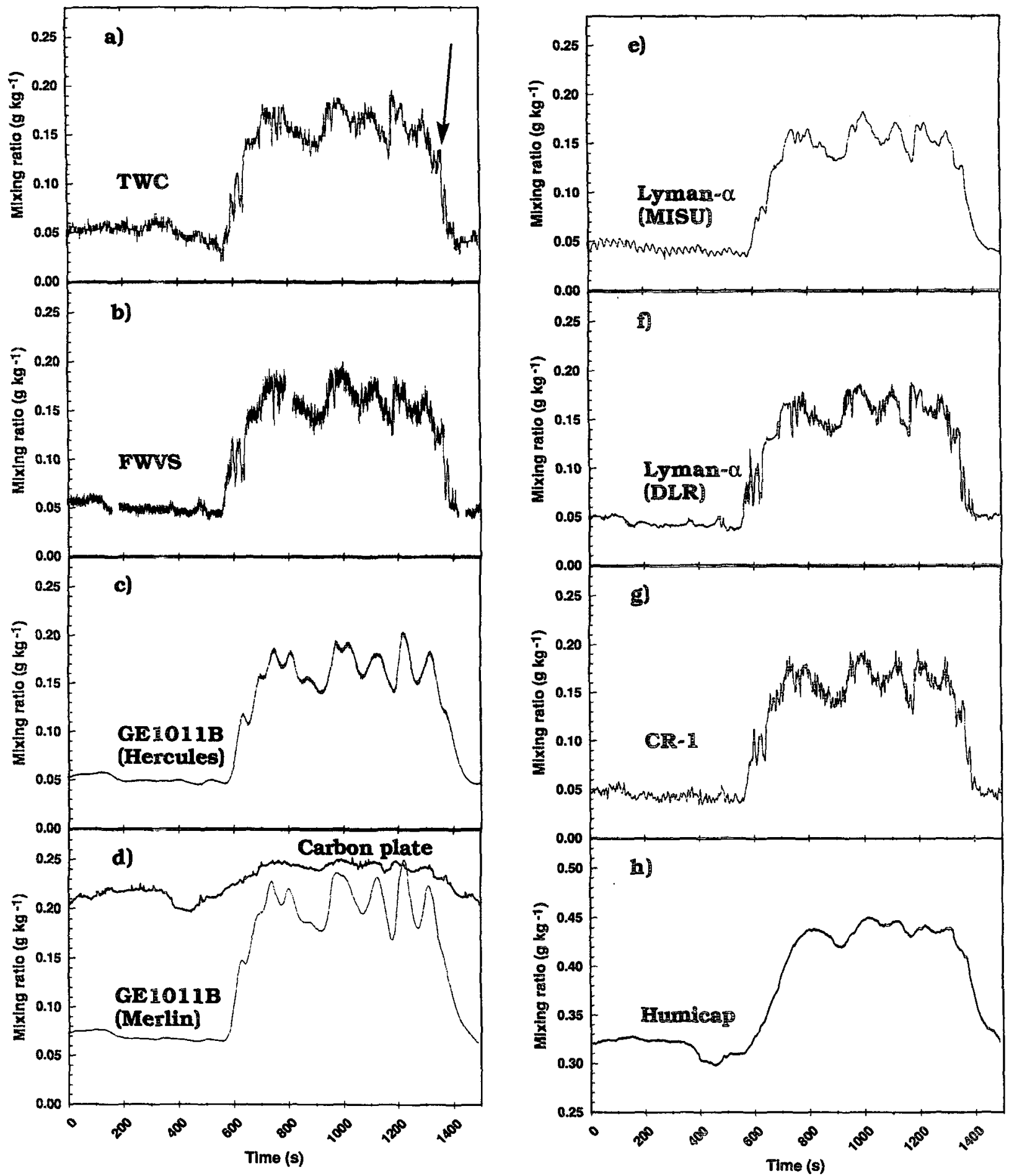

FIG. 2. Time series of mixing ratios measured between 1320 and 1345 UTC 22 January 1992 by (a) the total water content probe, (b) the fluorescence water vapor sensor, (c) the General Eastern 1011B dewpoint mirror (Hercules), (d) the General Eastern 1011B dewpoint mirror (Merlin) and the carbon plate hygrometer, (e) the Lyman- $\alpha$ hygrometer (MISU), (f) the Lyman- $\alpha$ hygrometer (DLR), (g) the cryogenically cooled dewpoint mirror, and $(h)$ the Vaisala Humicap instrument. Note the change of scale for the mixing ratio in Fig. $2 \mathrm{~h}$. 
shorter time constant than the electronically cooled mirrors. However, in comparison to the other instruments the jagged appearance of the signal suggests that the instrument overshoots and oscillates around the true value. This overshooting is most evident when comparing the signals from the CR-1 to the signals from the Lyman- $\alpha$ (DLR) (cf. Figs. $2 f$ and $2 g$ ). The overshoot of the CR-1 is probably an effect of the system that controls the mirror temperature. This problem has been significantly improved after the intercomparison (Busen and Buck 1993). The time series by the Lyman- $\alpha$ (MISU) does not present as many details as that for the Lyman- $\alpha$ (DLR). Low sample flow rate and long sampling lines resulted in a time lag of more than a minute (altitude dependent). Long residence time in the sample lines affected the instruments ability to resolve small-scale features, due to the internal mixing of the sample air. The instrument was also affected by electrical interference, which can clearly be seen during the time periods when the humidity was low during the first $600 \mathrm{~s}$ of the time series.

At the end of the time series in Fig. 2, the mixing ratio suddenly dropped about $0.14 \mathrm{~g} \mathrm{~kg}^{-1}$ to 0.04 $\mathrm{g} \mathrm{kg}^{-1}$. Assuming that this drop in humidity was a step change, we can graphically estimate a "worst case" time constant or $e$-folding time for the instruments. We have marked with an arrow in Fig. 2a where we assumed that the step change took place. The time constants for the TWC probe, FWVS, Lyman- $\alpha$ (DLR), and CR-1 were all better or much better than $20 \mathrm{~s}$. The time constants for the Lyman- $\alpha$ (MISU) and the GE1011B (Hercules) were better than 30 and $35 \mathrm{~s}$, respectively. The two instruments mounted on the Merlin did not resolve the feature that we used as the start of the step change well enough to yield an estimate of the time constant. A limiting time constant for the Humicap probe was difficult to assess, but seemed to be several minutes.

For the Lyman- $\alpha$ (DLR) and the TWC probe (the fastest instruments by comparison and relevant for flux calculations), we calculated power spectra, presented in Fig. 3, from flight segments conducted on the 23d at an altitude of $9000 \mathrm{~m}$. We consider the sampling conditions to be representative for the upper troposphere. The horizontal wind was about $25 \mathrm{~m} \mathrm{~s}^{-1}$ with light turbulence. The standard deviation for the vertical wind velocity on scales less than $5 \mathrm{~km}$ was about 0.2 $\mathrm{m} \mathrm{s}^{-1}$. The temperature was $-40^{\circ} \mathrm{C}$ and the average mixing ratio about $0.05 \mathrm{~g} \mathrm{~kg}^{-1}$. The spectra show excellent high-frequency response of the Lyman- $\alpha$ (DLR). The slope for the humidity compares well with the slope for the vertical wind for frequencies lower than $20 \mathrm{~Hz}$. The TWC probe reaches its noise level at about $1 \mathrm{~Hz}$. To a large extent, this noise can be attributed to the resolution with which the instrument signal is sampled by the data acquisition system (DAS) of the Hercules. Calculated water vapor fluxes for the two

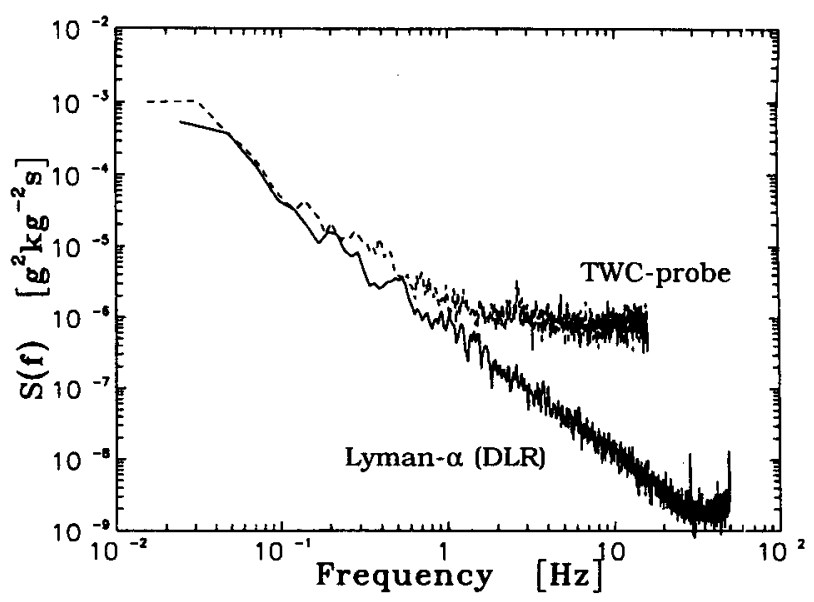

FIG. 3. Power spectra of the mixing ratio for the Lyman- $\alpha$ (LLR) hygrometer and the TWC probe. The spectra are averages of 20 spectra from individual segments with mean and trend removed from each segment.

instruments also compared well within the time resolution of the TWC probe.

To compare absolute mixing ratios we calculated averages for segments of lengths between 150 and $500 \mathrm{~s}$. The resulting average values of mixing ratios from 14 time periods are summarized in Table 1. To derive representative averages, the time periods were chosen for flight segments where the variation in the mixing ratio was limited. On the $21 \mathrm{st}$, the Lyman- $\alpha$ (MISU) and the TWC probe had data-logging problems and did not yield any results. For mixing ratios above 1 $\mathrm{g} \mathrm{kg}^{-1}$, the Lyman- $\alpha$ (MISU) could not be used due to saturation of its signal. In that state, too much of the UV light is absorbed by the water vapor in the sample chamber to yield reliable results. In some flights the Merlin could not participate because the operating altitude exceeded the maximum altitude of that aircraft. A graphical presentation of the values found in Table 1 is given in Fig. 4. The mixing ratios are plotted as a function of the values measured by the CR-1. The CR1 was chosen as a reference because it yielded independent results in all time segments. In terms of absolute humidity, the instruments agreed very well, except for the capacitance and resistance instruments. Evidently, the Humicap and the carbon plate instruments deviate from the other instruments as the mixing ratio decreases. The behavior of the Humicap instrument during the step change above suggests that this systematic deviation may be caused by a calibration problem. This could be significant in terms of improving humidity measurements from some operational radiosondes. However, the study by Busen (1991) suggests that this sensor behavior is not systematic and cannot be corrected for. After the intercomparison, the DLR has exchanged their HMP 11 for the new Vaisala HMP 25 unit. 
TABLE 1. A summary of the measured average mixing ratios $\left(\mathrm{g} \mathrm{kg}^{-1}\right)$ observed during the pre-EUCREX humidity intercomparison. The boldface indicates erroneous values excluded from the intercomparison, and the notation (na) indicates data not available.

\begin{tabular}{|c|c|c|c|c|c|c|c|c|c|c|c|c|c|}
\hline \multirow[b]{2}{*}{ Date } & \multirow[b]{2}{*}{ Time (UTC) } & \multicolumn{7}{|c|}{ Falcon } & \multicolumn{3}{|c|}{$C-130$} & \multicolumn{2}{|c|}{ Merlin } \\
\hline & & Seconds & $\begin{array}{c}\text { level } \\
\left(\times 10^{2} \mathrm{ft}\right)\end{array}$ & $\begin{array}{l}\text { Temp. } \\
\left({ }^{\circ} \mathrm{C}\right)\end{array}$ & CR-1 & Humicap & $\begin{array}{l}\text { Lyman- } \alpha \\
\text { DLR }\end{array}$ & $\begin{array}{c}\text { Lyman- } \alpha \\
\text { MISU }\end{array}$ & $\begin{array}{c}\mathrm{GE} \\
1011 \mathrm{~B}\end{array}$ & TWC & FWVS & $\begin{array}{c}\mathrm{GE} \\
1011 \mathrm{~B}\end{array}$ & $\begin{array}{c}\text { Carbon } \\
\text { plate }\end{array}$ \\
\hline 21 January 1992 & $\begin{array}{l}1403: 30-1409: 30 \\
1415: 00-1422: 00 \\
1450: 20-1455: 50 \\
1456: 00-1502: 25 \\
1508: 40-1516: 50\end{array}$ & $\begin{array}{l}360 \\
420 \\
330 \\
385 \\
490\end{array}$ & $\begin{array}{l}270 \\
270 \\
200 \\
200 \\
200\end{array}$ & $\begin{array}{l}-55 \\
-55 \\
-36 \\
-36 \\
-35\end{array}$ & $\begin{array}{l}0.031 \\
0.034 \\
0.240 \\
0.267 \\
0.276\end{array}$ & $\begin{array}{l}0.167 \\
0.164 \\
0.450 \\
0.466 \\
0.476\end{array}$ & $\begin{array}{l}0.029 \\
0.032 \\
0.236 \\
0.264 \\
0.273\end{array}$ & $\begin{array}{l}\text { na } \\
\text { na } \\
\text { na } \\
\text { na } \\
\text { na }\end{array}$ & $\begin{array}{l}0.034 \\
0.038 \\
0.250 \\
0.277 \\
0.286\end{array}$ & $\begin{array}{l}\text { na } \\
\text { na } \\
\text { na } \\
\text { na } \\
\text { na }\end{array}$ & $\begin{array}{l}0.040 \\
0.043 \\
0.246 \\
0.266 \\
0.262\end{array}$ & $\begin{array}{c}\text { na } \\
\text { na } \\
0.273 \\
0.300 \\
0.310\end{array}$ & $\begin{array}{c}\text { na } \\
\text { na } \\
0.320 \\
0.314 \\
0.310\end{array}$ \\
\hline 22 January 1992 & $\begin{array}{l}1320: 00-1325: 00 \\
1326: 00-1329: 20 \\
1334: 00-1338: 00 \\
1345: 40-1350: 45 \\
1452: 00-1454: 40 \\
1506: 40-1511: 30\end{array}$ & $\begin{array}{l}300 \\
200 \\
240 \\
305 \\
160 \\
290\end{array}$ & $\begin{array}{r}200 \\
200 \\
200 \\
200 \\
32 \\
6\end{array}$ & $\begin{array}{r}-23 \\
-23 \\
-23 \\
-23 \\
+1 \\
+3\end{array}$ & $\begin{array}{l}0.050 \\
0.046 \\
0.166 \\
0.050 \\
0.812 \\
3.214\end{array}$ & $\begin{array}{l}0.332 \\
0.315 \\
0.445 \\
0.312 \\
1.239 \\
3.301\end{array}$ & $\begin{array}{l}0.045 \\
0.046 \\
0.163 \\
0.050 \\
0.800 \\
3.264\end{array}$ & $\begin{array}{l}0.048 \\
0.042 \\
0.158 \\
0.042 \\
0.810 \\
\text { na }\end{array}$ & $\begin{array}{l}0.057 \\
0.053 \\
0.172 \\
0.053 \\
0.843 \\
3.449\end{array}$ & $\begin{array}{l}0.0567 \\
0.049 \\
0.166 \\
0.044 \\
0.822 \\
3.421\end{array}$ & $\begin{array}{l}0.056 \\
0.050 \\
0.168 \\
0.051 \\
0.027 \\
3.141\end{array}$ & $\begin{array}{l}0.077 \\
0.072 \\
0.209 \\
0.070 \\
0.868 \\
3.456\end{array}$ & $\begin{array}{l}0.220 \\
0.212 \\
0.212 \\
0.211 \\
0.902 \\
2.695\end{array}$ \\
\hline 23 January 1992 & $\begin{array}{l}1248: 45-1256: 25 \\
1259: 25-1303: 50 \\
1303: 55-1308: 55\end{array}$ & $\begin{array}{l}460 \\
265 \\
300\end{array}$ & $\begin{array}{l}280 \\
280 \\
280\end{array}$ & $\begin{array}{l}-40 \\
-40 \\
-40\end{array}$ & $\begin{array}{l}0.033 \\
0.045 \\
0.069\end{array}$ & $\begin{array}{l}0.177 \\
0.196 \\
0.196\end{array}$ & $\begin{array}{l}0.028 \\
0.042 \\
0.066\end{array}$ & $\begin{array}{l}0.028 \\
0.034 \\
0.058\end{array}$ & $\begin{array}{l}0.036 \\
0.047 \\
0.072\end{array}$ & $\begin{array}{l}0.043 \\
0.061 \\
0.072\end{array}$ & $\begin{array}{l}0.034 \\
0.078 \\
0.069\end{array}$ & $\begin{array}{l}\text { na } \\
\text { na } \\
\text { na }\end{array}$ & $\begin{array}{l}\text { na } \\
\text { na } \\
\text { na }\end{array}$ \\
\hline
\end{tabular}

Many of the participating instruments directly measure dew-/ frost point. As an example of the instrument performance in terms of average frost point. Figure 5 shows the results from four legs on 22 January. The information in Fig. 5 is essentially the same as in Fig. 4. We see that the instruments agree better for warmer frost points and that the largest deviation from the mean is found for the Humicap and carbon plate and to some extent the GE1011B (Merlin). The remaining instruments do not differ by more than about $2^{\circ}$ in frost point.

Although the mixing ratio is a physical measure of water content in the atmosphere, it is of interest to see what the relative difference between the instruments is at different mixing ratios. In want of an absolute reference method during in situ measurements, this information may be used as an indication of the uncer-

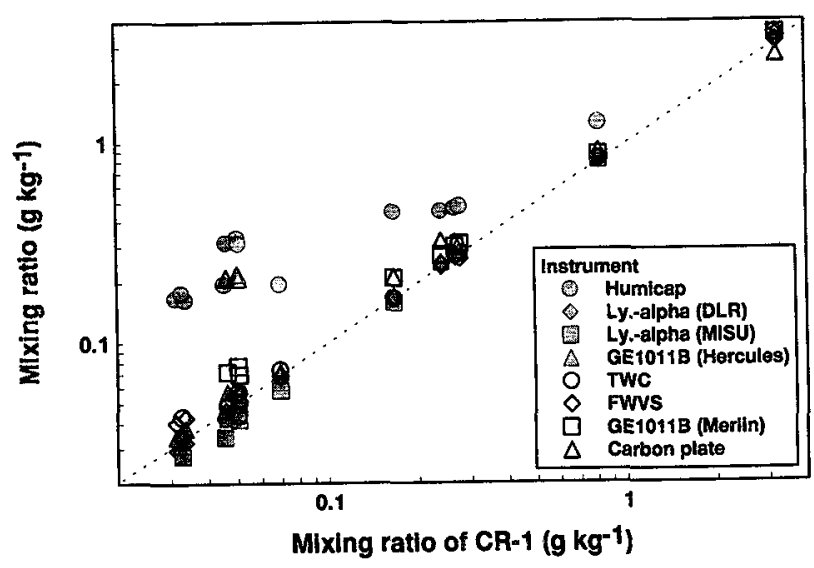

FIG. 4. Graphic presentation of the average values in Table 1. The measured mixing ratios are plotted as a function of the mixing ratio measured by the CR-1. The dashed line shows the one-to-one relation. tainty in the measurements. The relative instrument deviation from the measurement made by the $C \mathbb{R}-1$ is plotted in Fig. 6 as a function of the mixing ratio measured by the CR-1. If all instruments agreed perfectly, they would all fall on $0 \%$ independent of the actual mixing ratio. For mixing ratios down to around 0.1 $\mathrm{g} \mathrm{kg}^{-1}$ the instruments agreed within about $\pm 5 \%$. Below $0.1 \mathrm{~g} \mathrm{~kg}^{-1}$, the agreement was within about $\pm 15 \%$. For comparison, a mixing ratio of $0.1 \mathrm{~g} \mathrm{~kg}^{-1}$ is equivalent to water saturation at about $11-\mathrm{km}$ altitude in the International Civil Aeronautical Organization standard atmosphere. Figure 6 reveals some systematic differences between the instruments. With decreasing mixing ratio, the Lyman- $\alpha$ (DLR) and Lyman- $\alpha$ (MISU)

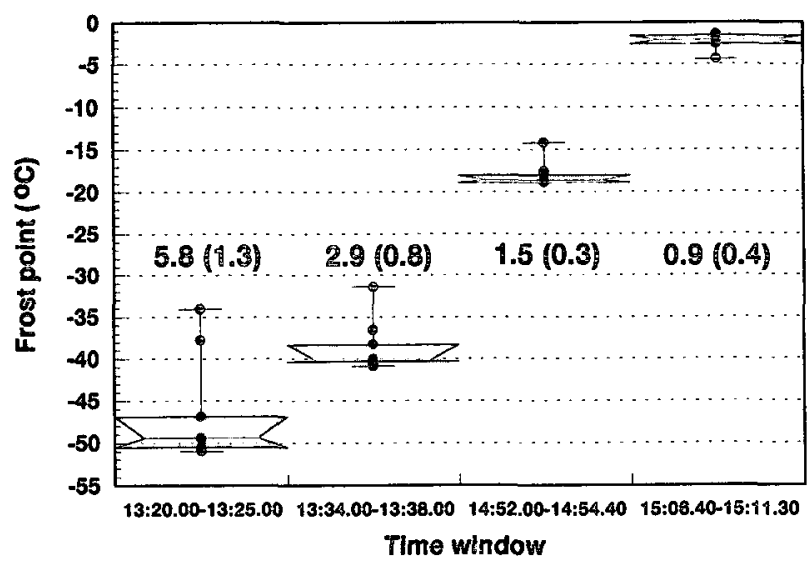

FIG. 5. Box-whisker plot showing the performance of the instruments in terms of frost point. The data are from four time windows on 22 January. The boxes separate the data into quartiles, while the whiskers define the outlying $5 \%$ of the data values. The numbers in the figure are the corresponding rms values. The rms values when excluding the Humicap and carbon plate instruments are shown in parentheses. 


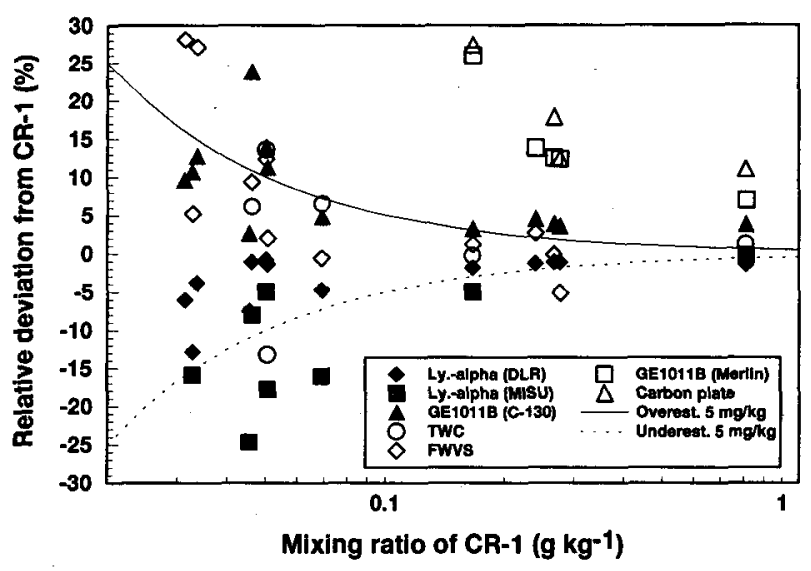

FIG. 6. Sensor comparison in terms of relative difference from the measurements made by the CR-1. The lines in the figure show the effect of an under- or overestimation of the ambient mixing ratio by $5 \mathrm{mg} \mathrm{kg}^{-1}$. The Vaisala Humicap instrument is of scale.

measure less water vapor in relation to the other instruments. In Fig. 6 we see that the Lyman- $\alpha$ (DLR) always measures mixing ratios less than or equal to that of the CR-1. Thus, the Lyman- $\alpha$ (DLR) would probably have measured lower values without the drift correction to the CR-1. The other instruments tend to measure higher water vapor contents as the mixing ratio decreases. In relation to the other instruments, the GE1011B (Merlin) and the carbon plate instruments clearly deviate toward higher values as the mixing ratio decreases. The Humicap instrument is off scale in Fig. 6.

To a large extent, the systematic differences in mixing ratios between many of the instruments can be explained by constant over- or underestimation of the water vapor content. The two lines in Fig. 6 show how an over- or underestimation of the mixing ratio by 5 $\mathrm{mg} \mathrm{kg} \mathrm{g}^{-1}$ would spread the measurements. A closer inspection of the data shows that the two independent instruments that agreed best in terms of average values were the FWVS and the Lyman- $\alpha$ (MISU). The difference between these two instruments was an offset of about $9 \mathrm{mg} \mathrm{kg}^{-1}$ ( $1.5 \mathrm{mg} \mathrm{kg}^{-1}$ standard deviation). This constant difference could be due to an underestimation of the water content in the dry reference air for the Lyman- $\alpha$ (MISU), the equations and algorithms used for the different instruments, or systematic differences in sensors for measuring quantities (temperature, pressure, and airflow) that enter the equations.

\section{Summary and conclusions}

With the exception of the capacitance and resistance instruments (Vaisala Humicap and carbon plate), we found good agreement between the participating instruments in the measured absolute mixing ratio over a wide range of values. In terms of relative humidity, the deviation between the instruments increased with decreasing mixing ratio. For mixing ratios down to around $0.1 \mathrm{~g} \mathrm{~kg}^{-1}$ the instruments agreed within about $\pm 5 \%$. Below $0.1 \mathrm{~g} \mathrm{~kg}^{-1}$ the instruments agreed within about $\pm 15 \%$. The systematic difference found between the instruments suggests that the use of different evaluation and conversion algorithms, systematic differences in measured temperature, pressure, and sample flow rate, etc., become increasingly important with decreasing vapor content. It is recommended that, when possible, the same conversion formulas and algorithms be used by the different participants in joint experiments.

The commonly used GE1011B dewpoint mirrors were able to resolve variations in the humidity on the 10-20-km scale even at temperatures a few degrees below $-20^{\circ} \mathrm{C}$ and absolute values of the mixing ratio between 0.05 and $0.20 \mathrm{~g} \mathrm{~kg}^{-1}$. The CR-1 appeared to accentuate the variations in mixing ratio by overshooting the true value. Nevertheless, the use of a cryogenically cooled mirror significantly improved the resolution compared to the thermoelectric element used in the GE1011B. The Lyman- $\alpha$ (DLR) was the instrument best suited for measuring relative changes in water vapor mixing ratios. At the nominal speed of the research aircraft Falcon, the instrument can resolve features on the $10-\mathrm{m}$ scale. Thus, at the moment it is the only instrument to be used for eddy-correlated water flux measurements. The other optical instruments [Lyman- $\alpha$ (MISU), TWC probe, and FWVS] did not show comparable time resolutions. These instruments should be able to perform better with an improved DAS on the Hercules and with a higher sampling flow rate in the Lyman- $\alpha$ (MISU) hygrometer. It should be mentioned that the design of the TWC probe was optimized for measurements at humidities much higher than were used in the intercomparison. Thus, the TWC probe would have performed better using the same DAS on the Hercules but interfaced differently to the instrument. The FWVS demonstrated the potential for rapid time response although this is presently masked by a higher instrumental noise level than on the L.yman- $\alpha$ (DLR), for example.

Acknowledgments. We thank the aircraft crews on Falcon, Hercules, and Merlin in always doing their best to meet the scientists needs and for excellent wing-bywing formation flying; the staff at MRF (Farnborough) for providing an excellent base for the experiment; Ken Dewey and Colin Hord of MRF for their work on the development and calibration of the FWVS; Danny McKenna for comments on the manuscript; Leif Bäcklin, Sven-Åke Odh, and Sune Moritz of MISU for their work on the CVI payload; the support by MétéoFrance for the participation of Merlin. Funding of EUCREX is part of the European Programme on Climatology and Natural Hazards, European Economic 
Community, Brussels, and is also supported by the Swedish Natural Science Research Council.

\section{REFERENCES}

Buck, A. L., 1985: The Lyman- $\alpha$ absorption hygrometer. Moisture and humidity, measurement and control in science and industry. Proc. Int. Symp. on Moisture and Humidity, Washington, DC, Instrument Society of America, 411-436.

- , and R. Clark, 1991: Development of a cryogenic dew/frost point hygrometer. Proc. Seventh Symp. on Meteorological Observations and Instrumentation, New Orleans, Amer. Meteor. Soc., 322-326.

Busen, R., 1991: Humidity measurements on the DLR aircraft. Second Symp. on Tropospheric Profiling, Boulder, $\mathrm{CO}, 167-$ 168.

aircraft use: Description, installation, and flight data. Institute für Physik der Atmosphäre, Report No. 10, DLR, Oberpfaffenhofen, Germany, 1-29.

- - - , and R. D. Horn, 1991: The DLR Lyman-a hygrometer. Proc. Seventh Symp. on Meteorological Observation and Instrumentation, New Orleans, Amer. Meteor. Soc., 316-321.
Kley, D., and E. J. Stone, 1978: Measurements of water vapor in the stratosphere by photodissociation with Ly- $\alpha(1216 \AA)$ light. Rev. Sci. Instrum., 6, 691-697.

Morrissey, J. F., and F. J. Brousaides, 1970: Temperature-induced errors in the ML-476 humidity data. J. Appl. Meteor., 9, 805808.

Nicholls, S., J. R. Leighton, and R. A. L. Barker, 1989: A new fast response instrument for measuring total water content from aircraft. J. Atmos. Oceanic Technol., 5, 705-718.

Noone, K. J., J. A. Ogren, J. Heintzenberg, R. J. Charlson, and D. S. Covert, 1988: Design and calibration of a counterflow virtual impactor for sampling of atmospheric fog and cloud droplets. Aerosol Sci. Tech., 8, 235-244.

Raschke, E., 1988: The international satellite cloud climatology project, ISCPP, and its European regional experiment ICE. Atmos. Res., 21, 191-201.

_- J. Schmetz, J. Heintzenberg, R. Kandel, and R. Saunders, 1991: The international cirrus experiment (ICE)-A joint European effort. ESA J., 更, 193-199.

Semiond, J. C., 1977: The measurement of atmospheric humidity with an aircraft (in French). Ph.D. thesis, University of Clermont-Ferrand, France, 157 pp.

Zuber, A., and G. Witt, 1987: Optical hygrometer using differential absorption of hydrogen Lyman- $\alpha$ radiation. Appl. Opt., 26, 30833089 . 